\title{
The Necessity of Family Type Interventions During First - Episode Psychosis in Schizophrenia
}

\section{Bianca Andreica-Săndică*}

University of Medicine and Pharmacology "Iuliu Hatieganu", Cluj-Napoca, Romania

\begin{abstract}
Losing hopes and dreams regarding a person diagnosed with schizophrenia-a first psychotic episode, emotional tribulation, going between remission and relapse, the risk of self-inflected wounds and of aggressiveness against people around, are experiences which families have to face.

Intrinsic family characteristics determine the way family members react to illness, with clear repercussions on both the family and the evolution of first - episode psychosis.

We shall next present the various family characteristics that might influence the evolution of a psychotic episode, as well as the results of some studies that show the efficiency of family interventions in the evolution of a first psychotic episode in schizophrenia.
\end{abstract}

Keywords: First psychotic episode; Schizophrenia; Family interventions

\section{Introduction}

Members of families where someone has been diagnosed with schizophrenia may feel burdened by their role as "caretakers", they may not be able to deal with the stress of having to care for a person with a pathology with such a serious prognosis, they may have massive personal costs or may not be able to look after the patient for long periods of time, which might have repercussions on their personal lives, on their capacity to help the patient, and on the evolution of the disease [1].

Antipsychotic medical treatment is the elective therapeutic intervention in first - episode psychosis in schizophrenia [2].

The same clinical manifestations produce different reactions in families, with repercussions on the evolution of schizophrenia. Various studies have tried to correlate certain family characteristics (level of expressed emotions, burden, attributing the cause of the disease, disease coping mechanisms, family member resources) with the evolution of the disease, and thus to support the obligativity of family type interventions in the patient's recovery process.

Chakrabarti and Kulhara [3] have shown that families of patients suffering from schizophrenia present higher burdening than families with affective or anxiety disorders.

The burdening and distress felt by family members are in accordance with the way the patient's problems are evaluated (the way the family members attach meaning to them) and with the identified personal resources $[4,5]$.

There have been studies [6,7] that aimed at determining the correlation between the type of symptoms and the level of burden felt by the family. Their results are not consequent that positive symptoms. It seems impact the entire family, but mostly the negative ones, which unlike the positive ones, are present all the time.

Birchwood and Cochrane [8], Magliano et al. [9] presented that there was a link between the coping mechanisms and family burdening.

Barrowclough et al. [10] have shown that assigning by family members to the cause of the psychosis is a better predictor of relapse than the level of expressed emotion (EE).

Multiple studies have demonstrated that a high level of expressed emotions is associated with high burdening in members of families of the schizophrenia patient [11-13] as well as with high risk of relapse [14-17].

Fewer studies [18-20] have evaluated the correlation between the EE level and the first psychotic episode and they are contradictory as to the relation between a high level of EE and relapses. A high level of EE has been found both in patients with chronic psychosis and in those having a first psychotic episode, and that it represents a valuable indicator of relapse [21-24]. According to other studies, EE is less pronounced in the early stages of psychosis, and criticism and hostility develop quickly during the first years of disease [25], in contrast with results of studies carried out in 12 countries for 40 years which signal a high level of criticism and rejection in families with chronic schizophrenia [26,27].

Early intervention is a desiderate in treating psychotic disorders, presently existing more than 200 centres all over the world [28] that offer specialised services addressed to the first psychotic episode. Some programmes addressed to the first psychotic episode Early Psychosis Prevention and Intervention Centre (EPPIC), Australia, The Early Treatment and Intervention of Psychosis (TIPS), Norway, Calgary Early Psychosis Program (EPP), Canada, The Recognition and Prevention of Psychological Problems (RAP), USA) also incorporate family intervention (family psychotherapy, psycho-educational multifamily group treatment) [28].

*Corresponding author: Bianca Andreica-Săndică, Lecturer , University of Medicine and Pharmacology "Iuliu Hatieganu", Cluj-Napoca, Romania, E-mail: sbandreica@yahoo.com

Received November 23, 2012; Accepted November 23, 2012; Published November 25, 2012

Citation: Andreica-Săndică B (2012) The Necessity of Family Type Interventions During First - Episode Psychosis in Schizophrenia. J Trauma Treat 1:e111. doi:10.4172/2167-1222.1000e111

Copyright: (C) 2012 Andreica-Săndică B. This is an open-access article distributed under the terms of the Creative Commons Attribution License, which permits unrestricted use, distribution, and reproduction in any medium, provided the original author and source are credited. 
The research study published by Penn et al. [29], a meta-analysis of the papers published between 1983 and 2004, regarding the efficiency of psychosocial interventions during the first psychotic episode, concluded that significant differences were noticed with respect to frequency of hospitalisation, number of hospitalisation days, a drop in positive symptoms, the amelioration of social functioning for the benefit of those who also took part in family therapy.

Following the analysis of 32 research studies which included 2429 subjects, the NICE (National Institute for Health and Clinical Excellence) guide for schizophrenia (2010) reached the conclusion that there is clear evidence of family type intervention efficiency in relapse risk, rate of hospitalisation, and symptom seriousness.

There have been concordant results between many studies [30-33] which discovered a rate of transition of the people with a very high risk of developing psychosis at a first psychotic episode of $40 \%$ within one year from being included in the risk group.

Until now, there are very few research studies [34,35] with modest results on the efficiency of antipsychotics on postponing the occurrence of the first psychotic episode and which necessitate reconfirmation.

The results of the family type interventions on the first psychotic episode represent a recommendation for initiating comparative studies with other types of psychotherapy (cognitive-behavioural therapy) [36] to confirm their efficiency for people with a very high risk of developing psychosis.

From the data presented, it is clear that further comparative research is needed on the efficiency of family type psychotherapy as opposed to other types of psychotherapy, to prove the necessity of compulsory introduction of family therapy in the management of the first schizophrenic episode, together with the consequences of this recommendation, namely the reorganisation of mental health policies and services.

\section{References}

1. Barrowclough C (2005) Families of people with schizophrenia. In: N Sartorius, J Leff, Lopez-lbor, Maj M, Okasha A (eds.). Families and Mental Disorders: From Burden to Empowerment, England, Wiley, 1-25.

2. Marder S, Jones P (2008) Schizophrenia. In: Tyrer P, Silk K (eds.). Effective Treatments in Psychiatry. Cambridge University Press 461-468.

3. Chakrabarti S, Kulhara P (1999) Family burden of caring for people with mental illness. Br J Psychiatry 174: 463.

4. Barrowclough C, Parle M (1997) Appraisal, psychological adjustment and expressed emotion in relatives of patients suffering from schizophrenia. $\mathrm{Br} J$ Psychiatry 171: 26-30.

5. Quinn J, Barrowclough C, Tarrier N (2003) The Family Questionnaire (FQ): a scale for measuring symptom appraisal in relatives of schizophrenic patients. Acta Psychiatr Scand 108: 290-296.

6. Fadden G, Bebbington $P$, Kuipers $L$ (1987) The burden of care: the impact of functional psychiatric illness on the patient's family. Br J Psychiatry 150: 285-292.

7. Jenkins JH, Schumacher JG (1999) Family burden of schizophrenia and depressive illness. Specifying the effects of ethnicity, gender and social ecology. Br J Psychiatry 174: 31-38.

8. Birchwood M, Cochrane R (1990) Families coping with schizophrenia: coping styles, their origins and correlates. Psychol Med 20: 857-865.

9. Magliano L, Fadden G, Economou M, Held T, Xavier M, et al. (2000) Family burden and coping strategies in schizophrenia: 1-year follow-up data from the BIOMED I study. Soc Psychiatry Psychiatr Epidemiol 35 109-115.

10. Barrowclough C, Johnson M, Tarrier N (1994) Attributions, expressed emotion, and patient relapse: an attributional model of relatives' response to schizofrenic illness. Behaviour Therapy 25: 67-88.
11. Kavanagh DJ (1992) Recent developments in expressed emotion and schizophrenia. Br J Psychiatry 160: 601-620.

12. King S, Ricard N, Rochon V, Steiger H, Nelis S (2003) Determinants of expressed emotion in mothers of schizophrenia patients. Psychiatry Res 117 : 211-222.

13. Scazufca M, Kuipers E (1996) Links between expressed emotion and burden of care in relatives of patients with schizophrenia. Br J Psychiatry 168: 580-587.

14. Brown GW, Birley JLT, Wing JK (1972) Influence of family life on the course of schizophrenic disorders: A replication. Br J Psychiatry 121: 241-263.

15. Hooley JM (1985) Expressed emotion: A review of the critical literature. Clinical Psychology Review 5: 119-139.

16. Leff J, Vaughn C (1985) Expressed Emotion in Families: It's Significance for Mental Illness. New York: Guilford Press.

17. Vaughn C, Leff J (1976) The measurement of expressed emotion in the families of psychiatric patients. Br J Soc Clin Psychol 15:157-165

18. Barbato A, D’Avanzo B (2000) Family interventions in schizophrenia and related disorders: A critical review of clinical trials. Acta Psychiatr Scand 102: 81-97.

19. Goldstein MJ (1985) Family factors that antedate the onset of schizophrenia and related disorders: The results of a fifteen year prospective longitudinal study. Acta Psychiatr Scand Suppl 319: 7-18.

20. Tienari PA, Wynne LC, Sorri A, Lahti I (2004) Genotype-environment interaction in schizophrenia-spectrum disorder. Long-term follow-up study of finish adoptees. Br J Psychiatry 184: 216-222.

21. Butzlaff R, Hooley JM (1998) Expressed emotion and psychiatric relapse. A meta-analysis. Arch Gen Psychiatry 55: 547-552.

22. McFarlane WR, Cook WL (2007) Family expressed emotion prior to onset of psychosis. Fam Process 46: 185-197.

23. Álvarez-Jiménez M, Gleeson JF, Cotton SM, Wade D (2010) Differentia predictors of critical comments and emotional over-involvement in first episode psychosis. Psychol Med 40: 63-72.

24. Schlooser DA, Zinberg JL, Loewy RL, Casey-Cannon S (2010) Predicting the longitudinal effects of the family environment on prodromal symptoms and functioning in patients at-risk for psychosis. Schizophr Res 118: 69-75.

25. Hooley JM and Richters JE (1995) Expressed emotion: A developmenta perspective. In: Cicchetti D, Toth SL (eds.). Emotion, cognition, and representation. Rochester, NY: University of Rochester Press 6: 133-166.

26. McFarlane WR, Cook WL (2007) Family Expressed Emotion Prior to Onset of Psychosis. Fam Process 46: 185-197.

27. Bebbington $P$, Kuipers $L$ (1994) The predictive utility of expressed emotion in schizophrenia: An aggregate analysis. Psychol Med 24: 707-718

28. Tecelli Domínguez Martínez, Joan Manel Blanqué, Jordi Codina, Mónica Montoro, Lluis Mauri, et al. (2011) Rationale and state of the art in early detection and intervention in psychosis. Salud Mental 34: 341-350.

29. Penn DL, Waldheter EJ, Perkins DO, Mueser KT, Lieberman JA (2005) Psychosocial Treatment for First-Episode Psychosis: A research Update. Am J Psychiatry 162: 2220-2232.

30. Yung AR, Phillips LJ, Yuen HP, Francey SM, McFarlane CA (2003) Psychosis prediction:12-month follow up of a high-risk ("prodromal") group. Schizophr Res 60: 2l-32.

31. Mason O, Startup M, Halpin S, Schall U, Conrad A (2004) Risk factors for transition to first episode psychosis among individuals with 'at-risk mental states'. Schizophr Res 71: 227-237.

32. Miller TJ, McGlashan TH, Rosen JL, Somjee J (2002) Prospective diagnosis of the initial prodrome for schizophrenia based on the Structured Interview for Prodromal Syndromes: preliminary evidenee of interrater reliability and predictive validity. Am J Psychiatry 159: 863-865.

33. Addington J, Cadenhead KS, Cannon TD, Cornblatt B, McGlashan TH (2007) North American Prodrome Longitudinal Study: a collaborative multisite approach to prodromal schizophrenia research. Schizophr Bull 33: 665-672.

34. McGlashan TH, Zipursky RB, Perkins D, Addington J, Miller T, et al. (2006) Randomized, Double-Blind Trial of Olanzapine Versus Placebo in Patients Prodromally Symptomatic for Psychosis. Am J Psychiatry 163: 790-799. 
Citation: Andreica-Săndică B (2012) The Necessity of Family Type Interventions During First - Episode Psychosis in Schizophrenia. J Trauma Treat 1:e111. doi:10.4172/2167-1222.1000e111

Page 3 of 3

35. McGorry PD, Yung AR, Phillips LJ, Yeun HP, Francey S, et al. (2002) Randomized controlled trial of interventions designed to reduce the risk of progression to the first-episode psychosis in a clinical sample with subthreshold symptoms. Arch Gen Psychiatry 59: 921-928.
36. Morrison AP, French P, Walford L, Lewis SW, Kilcommons A, et al. (2004) Cognitive therapy for the prevention of psychosis in people at ultra-high risk: Randomised controlled trial. Br J Psychiatry 185: 291-297. 